\title{
ELECTROCHEMILUMINESCENCT DETECTION OF METHAMPHETAMINE AND AMPHETAMINE
}




\begin{abstract}
Direct detection of amphetamine type stimulants (ATS) including methylamphetamine (MA) in street samples and biological matrices without the need for pretreatment or extraction is a great challenge for forensic drug analysis. Electrochemical techniques, such as electrochemiluminescence (ECL), are promising tools for this area of analysis. This contribution focuses on the electrochemical and photochemical properties of $\left[\mathrm{Ru}(\mathrm{bpy})_{3}\right]^{2+}$ nafion composite films and their subsequent use for the detection of ATS in particular MA. Under optimised conditions, the response linearly increased with the concentration over the concentration range $50 \mathrm{pM} \leq[\mathrm{MA}] \leq 1 \mathrm{mM}$ while an equivalent dynamic range was obtained for amphetamine with a correlation coefficient of 0.9903 and 0.9948 respectively. The ECL signal was monitored at $\sim 620 \mathrm{~nm}$, representing the $\lambda_{\max }$ for the $\left[\mathrm{Ru}(\mathrm{bpy})_{3}\right]^{2+}$ nafion composite films. This wavelength is shifted by approximately $15 \mathrm{~nm}$ compared to the photoexcited $\lambda_{\max }$ for the same system. The modified films were formed by direct interaction with the electrode surface without the need for surface modification or chain linkers. This is a major advantage for the fabrication of any sensor as it reduces the synthesis times resulting in more economically and cheaper production costs. This technique is simple, rapid, selective and sensitive, and shows potential for the high-throughput quantitation of ATS as well as possibilities for adaptation with other techniques such as FIA or LC systems.
\end{abstract}




\section{INTRODUCTION}

Methamphetamine (MA) has received much attention as an amphetamine type stimulant (ATS) drug that, even in small amounts, has a strong impact on the central nervous system causing mental alertness and other symptoms. ${ }^{1,2}$ It has been used to treat obesity and alcoholism, but it can cause physiological and psychological effects such as increased heart rate and blood pressure, affecting body temperature, attention and mood. It has also been reported as a widely abused drug in many areas of the world. ${ }^{3,4}$ As a result, the determination of MA has attracted much attention. Many chromatographic methods have been utilised for the identification and quantification of MA including gas chromatography (GC), ${ }^{5}$ HPLC, ${ }^{6}$ GC-MS, ${ }^{7}$ LC-MS, ${ }^{8}$ solid phase microextraction capillary electrophoresis ${ }^{9}$ and capillary electrophoresis electrochemical/ECL. ${ }^{10}$ The demand for portable, rapid and quantitative methods for the determination and analysis of illicit substances have been highlighted as the concerns over methamphetamine and amphetamine usage ${ }^{11}$ increase with growing concern over the situation within Europe. ${ }^{12}$ Techniques which have the ability to street samples and biological matrices without the need for pre-treatment or extraction is a great challenge for forensic drug analysis and this contribution will try to address this need through the application of ECL to the analysis of amphetamine and methampethamine. Current chromatographic methods generally involve time consuming derivatisation steps ${ }^{13-15}$ and/or extraction methods for biological samples. ${ }^{16}$ In this study, we present a simple and rapid ECL method as proof of concept for the detection and analysis of amphetamine and methamphetamine. ${ }^{17}$

ECL has been the subject of extensive study for the past three decades. ${ }^{18-22}$ The production of light from intermediates generated during electrolysis occurs when the energy liberated by reaction between the electrogenerated precursors is sufficient to generate a product in an electronically excited form. ${ }^{23}$ Studies of inorganic ECL have been dominated by transition metal complexes, ${ }^{24,25}$ particularly ruthenium poly(pyridyl) species, e.g., those of the general formula $\mathrm{Ru}(\mathrm{L}) 3_{3}{ }^{2+}$, e.g., where $\mathrm{L}=2,2^{\prime}$-bipyridine, ${ }^{26}$ or 4,7-diphenyl-1,10-phenanthroline. ${ }^{27}$ This is due to the attractive photophysical and electrochemical properties that these compounds typically exhibit.

ECL combines the inherent sensitivity, selectivity and linear range advantages of chemiluminescence methods with increased temporal and spatial control over the 
chemiluminescent reaction making ECL a powerful analytical tool, particularly when the surface may be modified to tune the ECL properties. Systems utilising both organic and inorganic complexes have been developed. ${ }^{18,28,29}$ ECL usually involves the reaction of electrogenerated species that react to form excited states, usually via an energetic redox reaction. ${ }^{18}$ Thus, ECL can also be utilized to probe electron and energy transfer processes at electrified interfaces. ${ }^{30,31}$ As such it has been used for the detection of alkylamines, $\mathrm{NADH}$, hydrazine, amino acids, biomolecules and a variety of pharmaceutical compounds. ${ }^{24,32,38}$

For example, one of the many applications of $\left[\mathrm{Ru}(\mathrm{bpy})_{3}\right]^{2+} \mathrm{ECL}$ is the detection of amino acids, ${ }^{34}$ and amine containing substances. ${ }^{35,36}$ A key advantage of ECL is that is offers the possibility of detecting very low concentrations of amino acids, i.e., sub nM, with good reproducibility by detecting both the current and light responses. Most detection systems involve the solution phase detection of amino acids or amine containing substances by ECL and flow injection analysis (FIA). ${ }^{37}$ However, changes in the micro environment of solution based analysis, including changes in viscosity, temperature, ion strength and $\mathrm{pH}$, can influence the resultant ECL. For example, Jackson et al. ${ }^{37}$ demonstrated that $\left[\mathrm{Ru}(b p y)_{3}\right]^{3+}$ generated in situ undergoes a chemiluminescent reaction with free amino acids. In agreement with previous studies, the chemiluminescence was maximized at $\mathrm{pH}$ values near the $\mathrm{p} K_{\mathrm{a}}$ of the N-terminal amine site. ${ }^{34}$ Similar results were obtained for ATS when electrochemically analysed in solution phase approaches..$^{35,36}$

There are several disadvantages to using solution phase reactants including loss of signal due to diffusion of the ECL reagent out of the detection zone, the limited ability to repeatedly electrochemically cycle an individual luminophore and high reagent consumption. To overcome these problems, considerable effort has been invested in immobilizing the $\left[\mathrm{Ru}(\mathrm{bpy})_{3}\right]^{2+}$ reagent on an electrode. ${ }^{34-37}$ This kind of reagentless ECL sensor can avoid external addition of reagents and can also overcome the limitation of reagent consumption since the $\left[\mathrm{Ru}(\mathrm{bpy})_{3}\right]^{3+}$ is regenerated in situ.

In this study, we report on the electrochemical, photophysical and electrochemiluminescent properties of $\left[\mathrm{Ru}(\mathrm{bpy})_{3}\right]^{2+}:$ Nafion composite films modified on glassy carbon electrodes. The surface coverage of the complex about $7.5 \times 10^{-9} \mathrm{~mol} \mathrm{~cm}^{-1}$, which is consistent with that expected for a composite film. The $\mathrm{Ru}^{2+/ 3+}$ couple is 
electrochemically reversible and the surface coverage is very stable over extended periods under voltammetric cycling. Significantly, emission is observed from the modified electrodes following photoexcitation or reaction of the electrochemically generated $\mathrm{Ru}^{3+}$ species with MA. This work has shown that the ruthenium composite film is suitable for the use in ECL detection of MA and could be extremely helpful in the development of portable quantitative systems for the detection of ATS over a forensically relevant linear range, minimizing the requirement for sample preparation. Ideally, this system could be used in combination to exploit this technology for a variety of illicit substances and this is an are in which future work would focus. 


\section{EXPERIMENTAL SECTION}

Materials. All the materials were purchased from Sigma-Aldrich and were used as received, with the exception of the interferent starch (BDN Laboratory Supplies) and the high purity methoal (Fluka). The controlled substances, MA and amphetamine, were purchased from Sigma-Aldrich in their salt forms. All concnentrations of these controlled ATS are quoted as free base concentrations.

Methods. Working electrodes were prepared by polishing with alumina $(1.0 \mu \mathrm{m}-0.3 \mu \mathrm{m})$ on a felt pad, followed by sonication in distilled deionized water for $30 \mathrm{~min}$. Where appropriate, working electrodes were modified by applying a drop $(\approx 15 \mu \mathrm{L})$ of an ethanolic solution of the $\left[\mathrm{Ru}(\mathrm{bpy})_{3}\right]^{2+}$ :Nafion film to the electrode surface. Stock solutions of Nafion$\left[\mathrm{Ru}(\mathrm{bpy})_{3}\right]^{2+}$ were prepared by dissolving $1 \mathrm{mg}$ of $\left[\mathrm{Ru}(\mathrm{bpy})_{3}\right]^{2+}$ in $2 \mathrm{~mL}$ methanol. Then, 200 $\mu \mathrm{L}$ of this solution was diluted in $1.8 \mathrm{~mL}$ of methanol and $200 \mu \mathrm{L}$ of Nafion $(5 \% \mathrm{w} / \mathrm{v}$ mixture of low molecular weight alcohols) was added. The mediator was found to precipitate at higher concentrations. The modified electrodes were then allowed to dry in the dark for 10 to 12 hours. The surface coverage, $\Gamma$, was determined by graphical integration of background corrected cyclic voltammograms $\left(<5 \mathrm{mV} \mathrm{s}^{-1}\right)$. In all cases the surface coverage were typically $\sim 7.5 \times 10^{-9} \mathrm{~mol} \mathrm{~cm}^{-1}$. All solutions were deoxygenated using nitrogen or argon prior to measurement.

Electrochemical experiments were performed in a standard electrochemical cell using a $\mathrm{CH}$ instruments (Memphis TN.) model 602E potentiostat. Cyclic Voltammetry experiments were carried out using a $3 \mathrm{~mm}$ diameter glassy carbon working electrode in a conventional three electrode assembly using a platinum flag as the counter electrode. Potentials were measured versus a standard $\mathrm{Ag} / \mathrm{AgCl}$ aqueous reference electrode (3M KCL). Measurements involving simultaneous detection of light and current utilised a $\mathrm{CH}$ instrument model 602E connected to a Hamamatsu H6780-20 PMT powered at $-600 \mathrm{~V}$. During the experiments, the cell was kept in a light-tight box in a specially designed holder where the working electrode was positioned directly opposite to the fibre optic bundle, the other end of which was coupled to the PMT. Emission spectra were recorded on a Cary Eclipse Fluorescence Spectrophotometer with an excitation and emission slits of $5 \mathrm{~nm}, 800 \mathrm{~V}$ PDA power and a scan rate of 120 $\mathrm{nm} / \mathrm{min}$. All other reagents used were of analytical grade, and all solutions were prepared in milli-Q water $(18 \mathrm{~m} \Omega \mathrm{cm})$. 


\section{RESULTS AND DISCUSSION}

Electrochemical properties of the glassy carbon electrode modified with the composite film containing $\left[R u(b p y)_{3}\right]^{3+}$ in Nafion.

The electrochemical behaviour of the $\left[\mathrm{Ru}(\mathrm{bpy})_{3}\right]^{2+}$ when surface confined within a nafion film on a GC electrode was examined using cyclic voltammetry. Figure 1 shows the typical voltammetric behaviour of the ruthenium modified electrode in $0.1 \mathrm{M} \mathrm{H}_{2} \mathrm{SO}_{4}$. The surface coverages were determined by graphical integration of background corrected cyclic voltammograms $\left(<5 \mathrm{mV} \mathrm{s}^{-1}\right)$ and were typically about $7.5 \times 10^{-9} \mathrm{~mol} \mathrm{~cm}^{-1}$, which is consistent with that expected for a composite film..$^{24,25,27}$ The anodic and cathodic peaks corresponding to the $\mathrm{Ru}^{2+/ 3+}$ couple are clearly visible at $1125 \mathrm{mV}$ and $1075 \mathrm{mV}$ respectively. The formal potential, $\mathrm{E}^{\circ}$, is within $25 \mathrm{mV}$ of that found for the complex dissolved in acetonitrile where the working electrode is a platinum microdisk. ${ }^{17}$ This observation indicates that the electron density of the metal centre does not change significantly upon surface immobilisation and that the composite film is highly solvated. In addition, the peak to peak separation between anodic and cathodic waves is close to zero at low scan rates, the full width at half maximum (FWHM) is close to the theoretically value of $59 \mathrm{mV}$ and the peak current varies linearly with the square root of the scan rate, as can be seen in Figure 1. Consistent with an electrochemically reversible reaction involving a surface confined reactant, the inset of Figure 1 shows that the peak current increases linearly with increasing scan rate for both oxidation and reduction processes.

This behavior is consistent with semi-infinite linear diffusion and under these conditions the response can be described by the Randles-Sevçik Equation;

$$
i_{p}=2.65 \times 10^{5} n^{3 / 2} A D_{c t} v^{1 / 2} C
$$

where $n$ is the number of electrons transferred, $A$ is the area of the working electrode, $D_{C T}$ is the diffusion coefficient, and $C$ is the concentration of the redox centers. ${ }^{38}$ The concentration of ruthenium centers within the composite film has been determined from density measurements in non-swelling solvents as $\sim 0.8 \mathrm{M}$. Thus, Equation 1 allows $D_{C T}$ to be estimated for both the oxidation and reduction processes of the $\mathrm{Ru}^{2+/ 3+}$ couple within the composite film. The $D_{C T}$ was calculated to be $2.1 \pm 0.7 \times 10^{-11} \mathrm{~cm}^{2} \mathrm{~s}^{-1}$ to be which is consistent with previous studies for similarly modified electrodes. ${ }^{20,21,24,25,38}$ Based on these $D_{C T}$ values it is possible to predict the regeneration rates of the $\mathrm{Ru}^{3+}$ species within each film according to the equation; ${ }^{39}$ 


$$
t=\delta^{2} / \pi D_{C T}
$$

where $\delta$ is the minimum dry thickness and using $D_{C T}$ calculated from equation 2 which indicates the time taken to fully oxidise the film and regenerate the $\mathrm{Ru}^{3+}$ mediating centres was $\sim 15 \mathrm{~s}$ for the composite film. Generally, faster regeneration rates are indicative of a larger and faster ECL intensity with a subsequent decrease in detection limits. ${ }^{39}$ However, these times are sufficient for the detection of methamphetamine.

ECL detection of methamphetamine. One of the key objectives of this work was to investigate whether the ability of a ruthenium nafion composite film to produce an ECL response upon interaction with methamphetamine. Figure 2 shows the ECL response for the RuNafion composite films upon interaction with MA. For the detection of amino acids and structurally similar chemicals such as MA, the electrogenerated $\left[\mathrm{Ru}(\mathrm{bpy})_{3}\right]^{3+}$ has been shown to undergo a mediated oxidation reaction with the amino acids moieties. Significantly, the chemiluminescent intensity is maximised at $\mathrm{pH}$ values near the $\mathrm{p} K_{a}$ of the N-terminal amine site $^{34-36,41}$ Experimental evidence in support of this mechanism has shown that the overall reaction efficiency depends strongly on the $\mathrm{pH}$ at which the reaction occurs and on the electron donating/withdrawing characteristics of the groups attached to the $\alpha$-carbon of the amino acid. ${ }^{33}$ Phosphate buffered solutions of MA with different $\mathrm{pH}$ ranging from 5 to 10 was investigated to investigate the effect of $\mathrm{pH}$ on the enhancement of ECL emission in the presence of $1 \mathrm{mM}$ MA. The optimal ECL response was obtained at $\mathrm{pH} 6$ which was therefore utilised throughout the study. This correlates with previous studies investigating the influence of $\mathrm{pH}$ on the behaviour of nafion films. ${ }^{20,35,36}$

The reaction between the electrogenerated $\mathrm{Ru}^{3+}$ and the MA undergoes a similar reaction process being sufficiently energetic to produce an ECL response. As with the reaction mechanisms for amino acids, MA and $\mathrm{Ru}^{2+}$ are simultaneously oxidised during a single potential step to produce $\mathrm{Ru}^{3+}$ and $\mathrm{MA}^{++}$respectively. The MA radical then loses a proton to form the strongly reducing species $\mathrm{MA}$ which reacts with the $\mathrm{Ru}^{3+}$ producing the excited state that emits light, according to equations $2-5$, which is similar to the mediated oxidation of several amino acids and oxalate. . $^{34,37,40}$

$$
\begin{aligned}
& {\left[R u(b p y)_{3}\right]^{2+} \leftrightarrow\left[R u(b p y)_{3}\right]^{3+}+e^{-}} \\
& {\left[R u(b p y)_{3}\right]^{3+}+C_{10} H_{15} N \rightarrow\left[R u(b p y)_{3}\right]^{2+}+C_{10} H_{15} N^{+}}
\end{aligned}
$$


$\left[R u(b p y)_{3}\right]^{3+}+C_{10} H_{15} N^{++}+H_{2} \mathrm{O} \rightarrow\left[R u(b p y)_{3}\right]^{2+*}+C_{9} H_{13} N^{++}+2 H^{+}+\mathrm{HCHO}$

$\left[R u(b p y)_{3}\right]^{2+*} \leftrightarrow\left[R u(b p y)_{3}\right]^{2+}+h v$

In the absence of MA, there is no ECL response, as is evident in Figure 2. However, in the presence of $1 \mathrm{mM} \mathrm{MA}$, the onset of light emission coincides closely with the onset of oxidative current where the potential of $\mathrm{Ru}^{3+}$ is generated. Despite no ECL emission being observed when MA was absent from the electrolyte, a typical voltammetric response for the ruthenium redox couple was observed. This behaviour is consistent with previous studies of amino acid ECL generation via interaction with ruthenium moieties ${ }^{20,34}$ and with the reaction mechanism described in equations 2 - 5. Experimental evidence in support of this mechanism has shown that the overall reaction efficiency depends strongly on the $\mathrm{pH}$ at which the reaction occurs and on the electron donating/withdrawing characteristics of the groups attached to the a-carbon of the amino acid. ${ }^{34,41}$ The ECL emission is centred at $620 \mathrm{~nm}$ which is slightly shifted compared to the luminescent intensity which is centred at $605 \mathrm{~nm}$, as shown in Figure 3. This figure also illustrates the emission spectrum in which a photo-excitation wavelength of $355 \mathrm{~nm}$ was utilised. The optically and electrochemically stimulated spectra are very similar in shape suggesting that both arise from a ${ }^{3}$ MLCT excited state. However, as noted, the wavelength of maximum emission for the ECL spectrum, at $620 \mathrm{~nm}$, is shifted to longer wavelengths by approximately $15 \mathrm{~nm}$ compared to the photoexcited spectrum. This behaviour has been observed previously for thin films of ruthenium and is indicative of a difference in energy between the ground and excited states usually being smaller for the electrochemiluminescence. ${ }^{33,34,38,39}$

Dynamic range for ECL detection of methamphetamine. The $\left[\mathrm{Ru}(\mathrm{bpy})_{3}\right]^{3+}$ based CL reaction is well suited to the detection of amine containing chemicals. This approach does not require chemical modification of the compound prior to detection, and the detection instrumentation and chemistry is relatively straightforward. However, for many applications in the field of forensic analysis, wide dynamic ranges and detection limits as low as $\mathrm{AM}$ may be required. ${ }^{7-}$ $9,35,36$

Figure 4 shows the ECL response increasing with increasing concentrations of MA over the concentration range $5 \times 10^{-9} \mathrm{M} \leq[\mathrm{MA}] \leq 1 \times 10^{-3} \mathrm{M}$. Figure 4 inset shows the dependence of the ECL intensity for the films on the concentration of MA. ECL occurs at a potential of approximately $1.1 \mathrm{~V} v s . \mathrm{Ag} / \mathrm{AgCl}$ as with the current response and increases linearly with 
increasing concentration of MA. The sensor response varies linearly with increasing MA concentration over this range with a limit of detection of $50 \mathrm{pM}$, as can be seen in Figure 5. The reproducibility of the modified electrode was also studied and a relative standard deviation of $4.8 \%$

Simultaneously recorded cyclic voltammogramms were obtained for all ECL responses obtained and these showed that peak currents could also be utilized for the detection and quantification of MA and other ATS. As noted, primary and secondary amines, such as amphetamine, can donate electrons to $\mathrm{Ru}$ (III) moieties, thereby producing light which is the basis of the ECL production in the system as can be seen from equations 2 - 5. Amphetamine was also found to produce an ECL response upon interaction with the ruthenium modified electrode as shown in Figure 6. However the magnitude/efficiency of this ECL signal varied dramatically. This trend has been previously reported for structurally similar amines. ${ }^{32,34,42}$ Figure 6 illustrates a typical calibration plot of ECL intensity verses amphetamine concentration over the range $5 \times 10^{-9} \mathrm{M} \leq$ [amphetamine] $\leq 1 \times 10^{-3} \mathrm{M}$. The system varies linearly with increasing amphetamine concentration over this range. The detection limits are lower than current chromatographic methods. It is possible that these detection limits could be further improved by incorporating the modified electrodes into a flow injection analysis (FIA) or microfluidic system which would also all for rapid onsite detection.

ECL signals were obtained for MA and amphetamine produce varying ECL intensities similar to previous studies investigating the differing response of primary and secondary amines. As reported by other investigators, the intensity is related to the $\mathrm{R}$ group of the amino acid, with CL intensity being greatest for amines with $\mathrm{R}$ groups that exhibit poor electron withdrawing characteristics. ${ }^{43,44}$

To further distinguish between the two closely related ATS, the simultaneously monitored amperometric response must be examined. The current response obtained for amphetamine is quite different from that obtained for the MA detection and can therefore be utilised to distinguish between the two ATSs, as can be seen in Figure 7. As with the MA solution, anodic current flow and light emission occur at similar potentials. The slopes of the ECL emission intensity with respect to potential for both ATS are indistinguishable. However, the inflection potential for the amphetamine, $0.90 \mathrm{~V}$, is approximately $20 \mathrm{mV}$ less positive than for MA. This result indicates that the oxidation of amphetamine at the modified surface is 
thermodynamically more facile than MA. It is perhaps important to note that limiting emission intensity is approximately an order of magnitude more for MA than for amphetamine. These observations suggest that while amphetamine reduces $\mathrm{Ru}^{3+}$ more efficiently the overall reaction it is not as efficient at producing the electronically excited state, $\mathrm{Ru}^{2+*}$. The additional oxidation peak observed for amphetamine is typical of the oxidation of the amine at this $\mathrm{pH}$ value. ${ }^{43,45}$

These detection limits are an order of magnitude out when compared to other systems available; however, previous methods are based on FIA analysis. By incorporating these modified electrodes into an FIA system or microfluidic system, which can be used to introduce a precisely defined quantities of the sample into the detection cell in order to optimize further the ECL response, the sensitivity should be greatly improved, possibly below the methods available at present.

In order to determine the wider spread viability and cross reactivity of this system, the influence of interferents commonly found in MA samples (glucose, starch, lactic acid, ascorbic acid, caffeine, and amphetamine) on the ECL response of this sensor were examined. As illustrated in Figure 8 none of these had any appreciable effect on the observed ECL intensity indicating good sensor specificity. Amphetamine showed the highest influence on the ECL emission but a false positive or over estimation of the concentration of MA present could be eliminated by simultaneously examining both the ECL and amperometric responses. Therefore, it was still possible to accurately quantify the MA present. This also highlights the possible application of this technique to quantification of MA in street samples and biological samples without the need for extraction or preconcentration. Adaptation of this technology with disposable electrodes is currently a focus of future work. 


\section{CONCLUSION}

In summary, this work highlights a proof-of-concept example for a new, robust and feasible ECL sensor for the determination of MA with high sensitivity. We have highlighted the ability of the simultaneous amperometric and ECL responses to discriminate between MA and amphetamine while illustrating sensitive pM detection. More importantly, this example paves the way for a broader application of ECL and amperometric sensors within forensic science and improving the translation of these techniques into the forensic arena. The authors anticipate that in combining the selectivity of the amperometric response with low background detection techniques such as ECL, there exists much potential for the development of a new generation of sensitive, selective and rapid forensic chemical sensors as well a significant scope for the improvement of existing systems, all with a common goal of improving portable on site chemical detection systems. 


\section{CONFLICT OF INTEREST}

The authors have no conflict of interest to report. 


\section{REFERENCES}

${ }^{1}$ RCW Hall, MK Popkin, TP Beresford, Amphetaime psychosis: Clinical presentations and differential diagnosis, Psych Med, 1988, 6, 73-79.

${ }^{2} \mathrm{H}$ Dai, Y Wang, X Wu, L Zhang, G Chen, An electrochemiluminescent sensor for methamphetamine hydrochloride based on multiwall carbon nanotube/ionic liquid composite electrode, Biosensors Bioelectronics, 2009, 24, 1230-1234.

3 UNODC World Drug Report, 2015 Available online from http://www.unodc.org/documents/wdr2015/World Drug Report 2015.pdf $\quad$ (assessed 17 July 2015).

${ }^{4}$ European Drug Report 2015, Available online from http://www.emcdda.europa.eu/edr2015 (assessed 18th July 2015).

${ }^{5}$ H Inoue, K Kuwayama, YT Iwata, T Kanamori, K Tsujikawa, H Muyaguchi, Simple and simultaneous detection of methamphetamine and dimethyl sulfone in crystalline methamphetamine seizures by fast chromatography, Forensic Toxicol, 2008, 26 19-22.

${ }^{6}$ X Chen, Analysis of Methamphetamine in Human Urine Using Ionic Liquid Dispersive Liquid-Phase Microextraction Combined with HPLC, Chromatographia, 2015, 78 (7) 515520.

${ }^{7}$ J Welter, P Kavanagh, MR Meyer, HH Mauerer, Benzofuran analogues of amphetamine and methamphetamine: studies on the metabolism and toxicological analysis of 5-APB and 5MAPB in urine and plasma using GC-MS and LC-(HR)-MS ${ }^{\mathrm{n}}$ techniques, Anal Bioanal Chem 2015, 407, 1371-1388.

${ }^{8}$ T Zhang, X Chen, R Yang, Y Xu, Detection of methamphetamine and its main metabolite in fingermarks by liquid chromatography-mass spectrometry, Forensic Sci Int, 2015, 248, $10-14$.

${ }^{9}$ M Rezazadeh, Y Yamini, S Seidi, Application of a new nanocarbonaceous sorbent in electromembrane surrounded solid phase microextraction for analysis of amphetamine and methamphetamine in human urine and whole blood, J Chromatogr A, 2015, 1396, 1-6.

${ }^{10}$ JY Sun, XY Xu, CY Wang, TY You, Analysis of amphetamines in urine with liquid-liquid extraction by capillary electrophoresis with simultaneous electrochemical and electrochemiluminescence detection. Electrophoresis, 2008, 29, 3999-4007.

${ }^{11}$ JG Bramness, MJ Reid, KF Solvik, V Vindenes, Recent trends in the availability and use of amphetamine and methamphetamine in Norway, Forensic Sci Int, 2015, 246, 92-97. 
12 EMCDDA Prespective on Drugs. Synthetic Drug Production in Europe. EMCDDA (2013) http://www.emcdda.europa.eu/topics/pods/synthetic-drug-production (accessed $01.12 .15)$

13 T Wang, B Shen, Y Shin, P Xiang, Z Yu, Chiral separation and determination of R/Smethamphetamine and its metabolite R/S-amphetamine in urine using LC-MS/MS, Forensic Sci Int, 2015, 246, 72-79.

${ }^{14}$ L.F. Martins, M. Yegles, H. Chung, R. Wenning, Sensitive, rapid and validated gas chromatography/negative ion chemical ionization-mass spectrometry assay including derivatisation with a novel chiral agent for the enantioselective quantification of amphetamine-type stimulants in hair. J Chromatogr. B, 2006, 842, 98-105.

15 S.M. Wang., T.C. Wang, Y.S. Giang, Simultaneous determination of amphetamine and methamphetamine enantiomers in urine by simultaneous liquid-liquid extraction and diastereomeric derivatisation followed by gas chromatographic-isotope dilution mass spectrometry, J. Chromatogr. B, 2005, 816, 131-143.

16 C. Chafer-Pericas, P. Campins-Falco, R- Herraez, Application of solid-phase microextraction combined with derivatisation to enantiomeric determination of amphetamines. J. Pharm. Biomed. Anal. 2006, 40, 1209-1217.

${ }^{17}$ Y.T. Iwata, H. Inoue, K. Kuwayama, T. Kanamori, K. Tsujikawa, H. Miyaguchi, T. Kishi, Forensic application of chiral separation of amphetamine type stimulants to impurity analysis of seized methamphetamine by capillary electrophoresis, Forensic Sci Int, 2006, 161, 92-96.

${ }^{18}$ (a) P. Bertoncello, A.J. Stewart, L. Dennany, Analytical Applications of Nanomaterials in Electrogenerated Chemiluminescence Anal. Bioanal. Chem., 2014, 406(23), 5573-5587. (b) Whole blood electrochemiluminescent detection of dopamine, A.J. Stewart, J. Hendry, L. Dennany, Anal Chem, 2015, 87 (23) 11847-11853..

19 A.W. Knight, G.M. Greenway, Relationship between structural attributes and observed electrogenerated chemiluminescence (ECL) activity of tertiary amines as potential analytes for the tris(2,2-bipyridine)ruthenium(II) ECL reaction. A review, Analyst 1996, 121, 101R106R.

20 TM Downey, TA Nieman, Chemiluminescence detection using regenerable tris $\left(2,2^{\prime}-\right.$ bipyridyl)ruthenium(II) immobilized in Nafion, Anal. Chem., 1992, 64(199) 261-268.

21 A. Devadoss, L. Dennany, C. Dickinson, T.E. Keyes, R.J. Forster, Highly Sensitive Detection of NADH using Electrochemiluminescent Nanocomposites, Electrochem. Commun., 2012, 19, 43-45 
L.Dennany, M.Gerlach, S. O’Carroll, T.E. Keyes, R.J. Forster, P.Bertoncello, Electrochemiluminescence (ECL) Sensing Properties of Water Soluble Core-Shell CdSe/ZnS Quantum Dots/Nafion Composite Films J. Mater. Chem, 2011, 21, 13984-13990.

${ }^{23}$ J.-K. Lee; D. S. Yoo; E. S. Handy;MF Rubner, Thin film light emitting devices from an electroluminescent ruthenium complex, Applied Physical Letters 1996, 69, 1686-1688.

${ }^{24}$ L. Dennany, P.C. Innis, G.G. Wallace, R.J. Forster, Reversible Photoinduced Electron Transfer in a Ruthenium Poly(2-methoxyaniline-5-sulfonic acid) Composite Film. J. Phys. Chem. B, 2008, 112 (41), 12907-12912

25 L. Dennany, E.J. O'Reilly, P.C. Innis, G.G. Wallace and R.J. Forster, Solid State Photochemistry of Novel Composites containing Luminescent Metal Centres and Poly(2methoxyaniline-5-sulfonic acid) J. Phys. Chem. B, 2009, 113 (21), 7443-7448.

26 O. Haas, M Kierns, JG Vos, An electrochemical investigation of photosubstitution processes at glassy-carbon electrodes coated with polymer-bound ruthenium complexes, J Am Chem Soc 1981, 103, 1318-1319.

${ }^{27} \mathrm{P}$ Qu, DW Thompson, GJ Meyer, High-pressure studies of photoluminescence properties of ruthenium(II) polypyridyl complexes, Langmuir 2000, 16, 4662-4671.

${ }^{28}$ Z. Mohsan, A.L. Kanibolotsky, A.J. Stewart, A. Regis Inigo, L. Dennany, P.J. Skabara, Electrochemistry and Electrogenerated Chemiluminescence of Trigonal QuaterfluoreneTruxene Star-Shaped Structures with Fused 2,1,3-Benzothiadiazole Units, J Mater Chem C, $2015,3,1166-1171$.

${ }^{29}$ L. Dennany, Z. Mohsan, A.L. Kanibolotsky, P.J. Skabara, Novel Electrochemiluminescent Materials for Sensor Applications, Faraday Dis., 2014, 174, 357-367

${ }^{30}$ L.R. Faulkner and A.J. Bard, in Electroanalytical Chemistry, A.J. Bard, Editor. Marcel Dekker: New York, 1-95, 1977.

${ }^{31}$ A.W. Knight and G.M. Greenway, Occurrence, mechanisms and analytical applications of electrogenerated chemiluminescence - review, Analyst, 1994. 119, 879-890.

${ }^{32}$ E.J. O’Reilly, P. Conroy, T.E. Keyes, R. O’Kennedy, R.J. Forster, L. Dennany, Combining recombinant Antibody technology and highly sensitive Electrochemiluminescence for the detection of the Cardiac Biomarker C-Reactive protein at sub fg Limits of Detection, RSC Advances, 2015, 5, 68874-67877.

33 A.J. Stewart, E.J. O'Reilly, P. Bertoncello, T.E. Keyes, R.J. Forster, L. Dennany, A Cholesterol Biosensor based on the NIR Electrogenerated-Chemiluminescence (ECL) of water-soluble CdSeTe/ZnS quantum dots Electrochimica Acta., 2015,157, 8-14. 
${ }^{34}$ L. Dennany, E.J. O’Reilly, T. Keyes, R.J. Forster. Electrochemiluminescenct monolayers on metal oxide electrodes: Detection of amino acids. Electrochem. Comm. 2006, 8, 15881594

35 H Dai, Y Wang, X Wu, L Zhang, G Chen, An electrochemiluminescent sensor for methamphetamine hydrochloride based on multiwall carbon nanotube/ionic luquid composite electrode, Biosensors Bioelectronics, 2009, 24, 1230-1234.

${ }^{36} \mathrm{Z}$ Cai, Z Lin, X Chen, T Jia, P Yu, X Chen, Electrochemiluminescence detection of methamphetamine based on a $\mathrm{Ru}(\mathrm{bpy}){ }_{3}{ }^{2+}$-doped silica nanoparticle/Nafion composite film modified electrode, Luminescence, 2010, 24, 367-372.

${ }^{37}$ W.A. Jackson, and D.R. Bobbitt, Chemiluminescent detection of amino acids using in situ generated $\mathrm{Ru}(\mathrm{bpy}) 3^{3+}$, Anal. Chim. Acta, 1994. 285, 309-320.

${ }^{38}$ E.J. O’Reilly, T.E. Keyes, R.J. Forster, L. Dennany, Insights into Electrochemiluminescent Enhancement Through Electrode Surface Modification Analyst, 2013, 138(2), 677-682.

${ }^{39}$ L. Dennany, E.J. O’Reilly, P.C. Innis, G.G. Wallace and R.J. Forster, The Influence of Poly(2-Methoxyaniline-5-sulfonic acid) on the Electrochemical and Photochemical Properties of a Highly Luminescent Ruthenium Complex, Electrochimica Acta, 2008, 53(13), 4599-4605.

${ }^{40}$ K.M. Omer, A.L. Kanibolotsky, P.J. Skabara, I.F. Perepichka and A.J. Bard, A.J. J. Phys. Chem. B.2007, 111, 6612-6619.

${ }^{41} \mathrm{SN}$ Brune, DR Bobbitt, Effect of $\mathrm{pH}$ on the reaction of tris(2,2'-bipyridyl)ruthenium (III) with amino-acids: implications for their detection. Talanta, 1991, 38(4), 419-424.

${ }^{42}$ L. He, K.Cox, N.D. Danielson, Anal. Letters, 1990, 23, 195-210.

${ }^{43}$ S.N. Brune and D.R. Bobbitt, Anal. Chim. Acta, 1994, 285, 309-328.

${ }^{44}$ F. Kanoufi, Y. Zu and A.J. Bard, J. Phys. Chem. B, 2001, 105, 210-216.

45 EM Garrido, JM Garrido, N Milhazes, F Borges, AM Oliveria-Brett, Electrochemical oxidation of amphetamine-like drugs and application to electroanalysis of ecstasy in human serum, Bioelectrochem, 2010, 79(1), 77-83. 


\section{LEGENDS}

Figure 1: Typical cyclic voltammogram of a composite film of $\left[\mathrm{Ru}(\mathrm{bpy})_{3}\right]^{2+}: \mathrm{Nafion}$ modified on a GC electrode. Electrolyte was $0.1 \mathrm{M} \mathrm{H}_{2} \mathrm{SO}_{4}$, and a scan rate of $100 \mathrm{mVs}^{-1}$ was used. Insert shows the scan rate dependence of the peak current for monolayer in sulphuric acid electrolyte, $10<v<100 \mathrm{mVs}^{-1}$.

Figure 2: Potential dependence of ECL intensity of a modified electrode in 0.1 M PBS solution containing (blue line) $1 \mathrm{mM}$ MA and without MA (red line) (pH 6). Scan rate of 100 $\mathrm{mVs}^{-1}$.

Figure 3. ECL Spectrum (b) of modified composite film on FTO electrode in contact with a solution containing $0.1 \mathrm{M}$ PBS and approximately $1 \mathrm{mM}$ MA (pH 6) and (b)the photoluminescence spectrum the same modified composite film in contact with $0.1 \mathrm{M}$ PBS. Excitation was by means of a $10 \mathrm{~ns}$ laser pulse $(355 \mathrm{~nm})$.

Figure 4: Dependence of the ECL emission intensity on the MA concentration. From top to bottom at $+1.2 \mathrm{~V}$, the concentrations of MA range from $1 \mathrm{mM}$ to $50 \mathrm{pM}$. Not all ECL responses are shown. The inset shows dependence of the maximum ECL intensity on [MA]. The error bars are comparable to, or smaller than, the size of the symbols.

Figure 5: Potential dependence of ECL intensity of a modified electrode in $0.1 \mathrm{M}$ PBS solution containing (blue line) $50 \mathrm{pM} \mathrm{MA}$ and without MA (red line) (pH 6). Scan rate of $100 \mathrm{mVs}^{-1}$.

Figure 6: Typical calibration plot of ECL intensity versus amphetamine concentration over the concentration range of $50 \mathrm{pM}$ to $1 \mathrm{mM}$. 
Figure 7: Typical cyclic voltammogram of a composite film of $\left[\mathrm{Ru}(\mathrm{bpy})_{3}\right]^{2+}: \mathrm{Nafion}$ modified on a GC electrode in the present of $1 \mathrm{mM}$ MA (blue dashed line) and $1 \mathrm{mM}$ amphetamine (red line) in $0.1 \mathrm{M}$ PBS (pH 6).

Figure 8: Dependence of the ECL response at $1.05 \mathrm{~V}$ for the $\left[\mathrm{Ru}(\mathrm{bpy})_{3}\right]^{2+}$ :Nafion in $1 \mathrm{mM}$ MA only, then with $10 \mathrm{mM}$ caffeine (Caf), $10 \mathrm{mM}$ glucose (Glu), $10 \mathrm{mM}$ lactic acid (LA), 10 $\mathrm{mM}$ ascorbic acid (AA), $10 \mathrm{mM}$ starch and $10 \mathrm{mM}$ amphetamine (Amph). Error bars represent triplicate data points. 
FIGURE 1

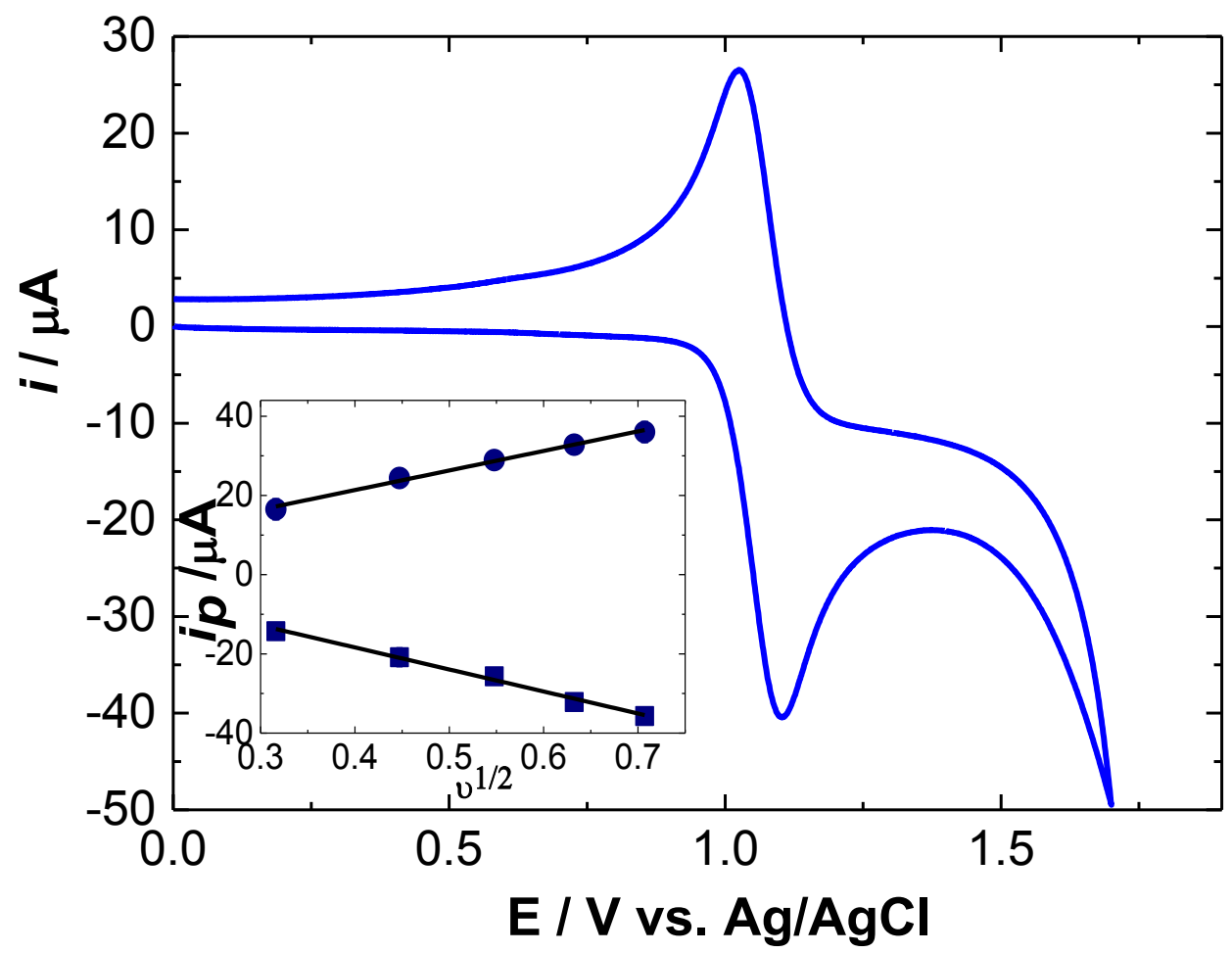


FIGURE 2

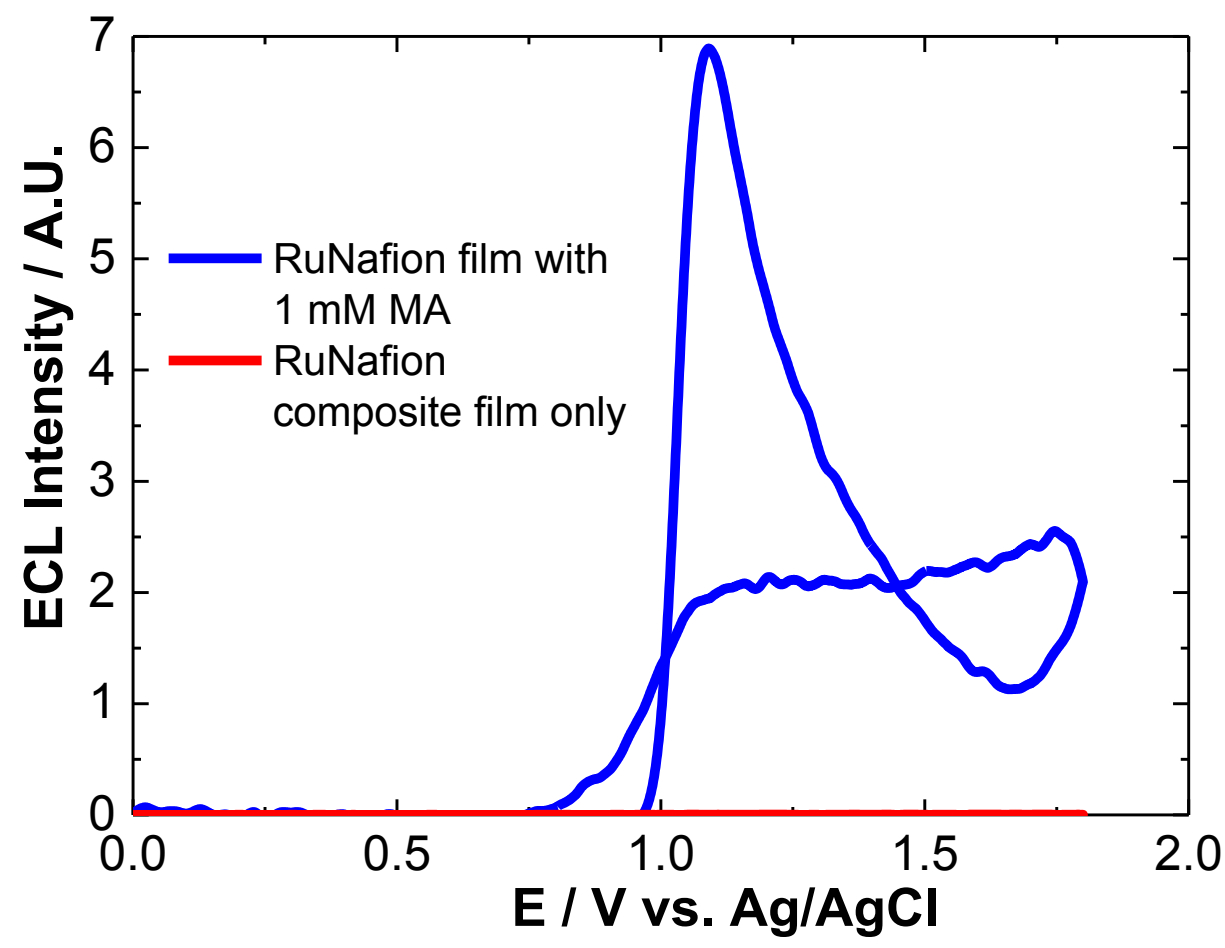


FIGURE 3

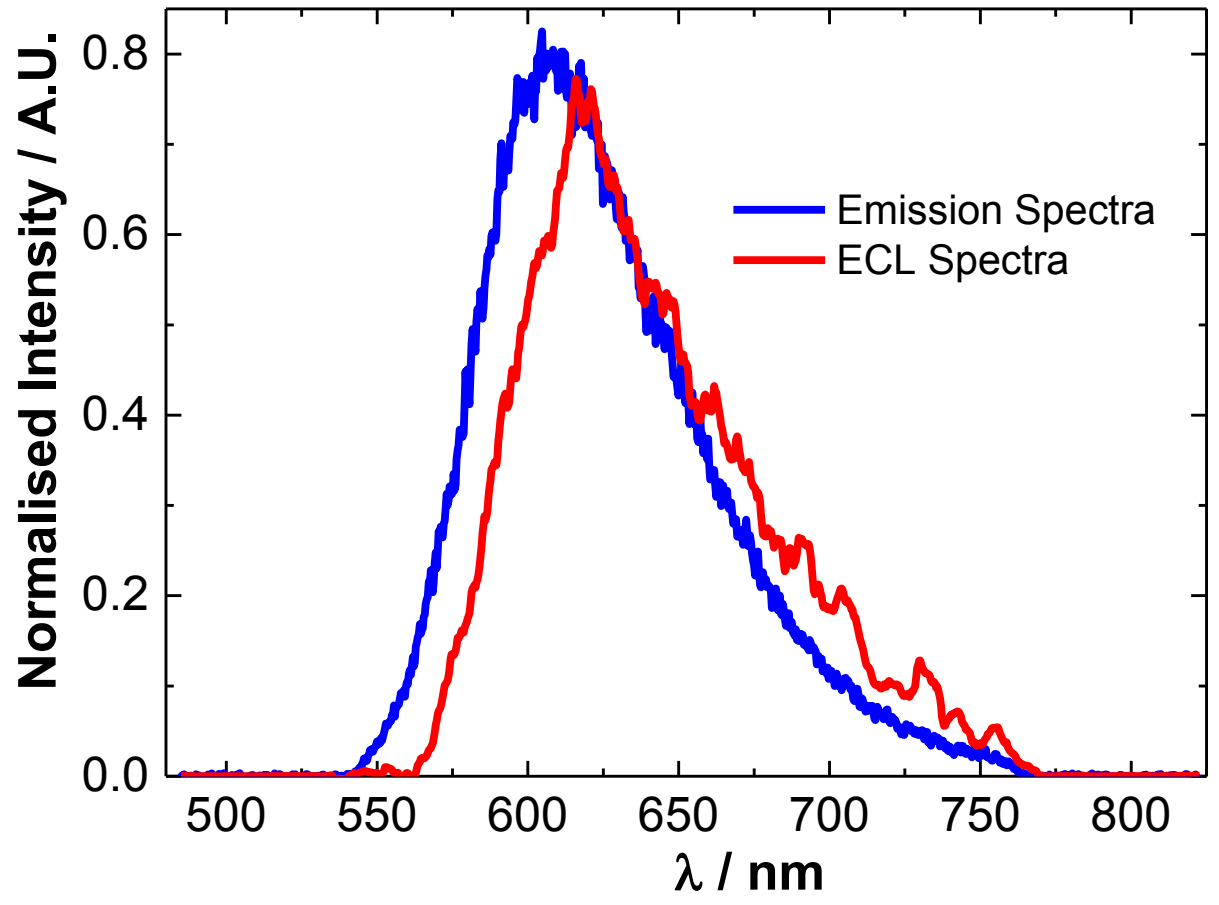


FIGURE 4

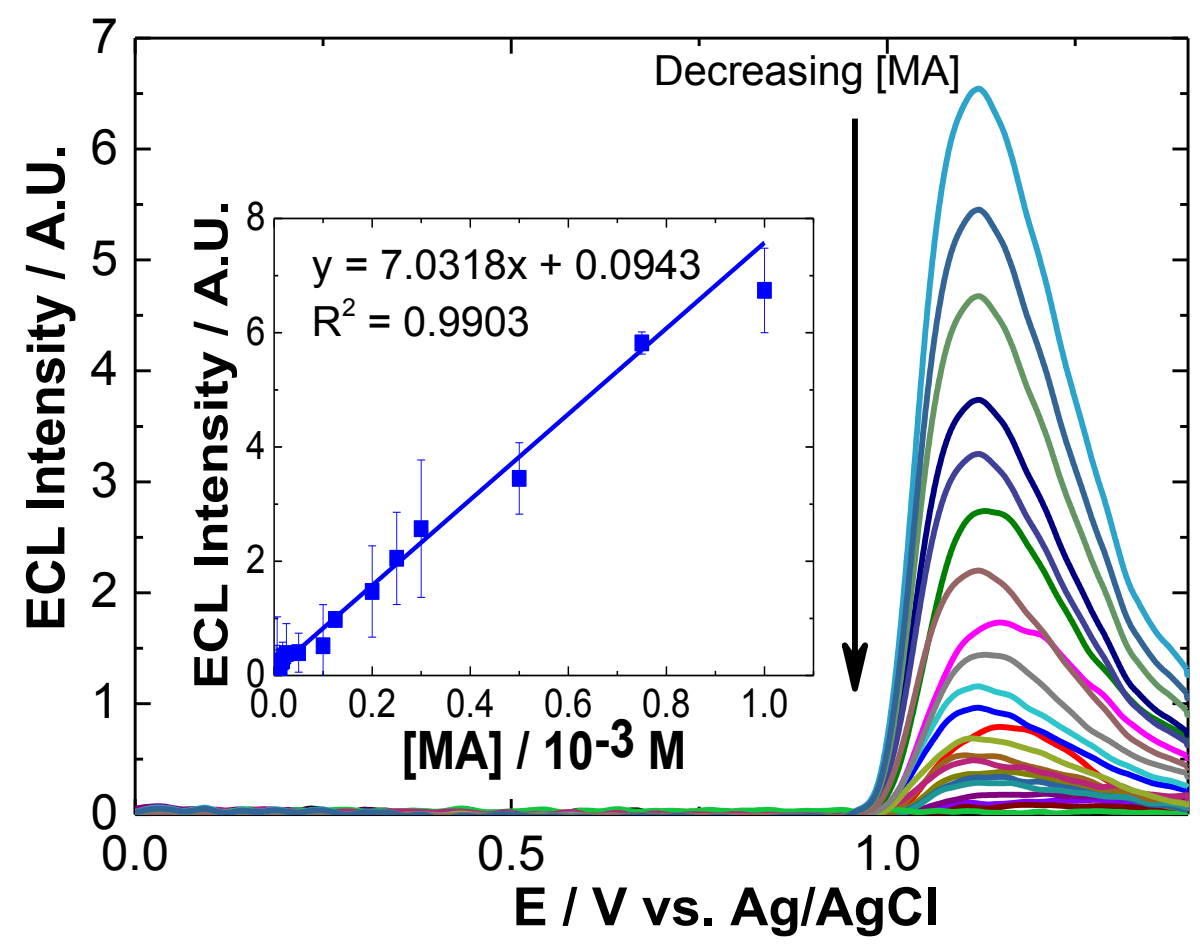


FIGURE 5

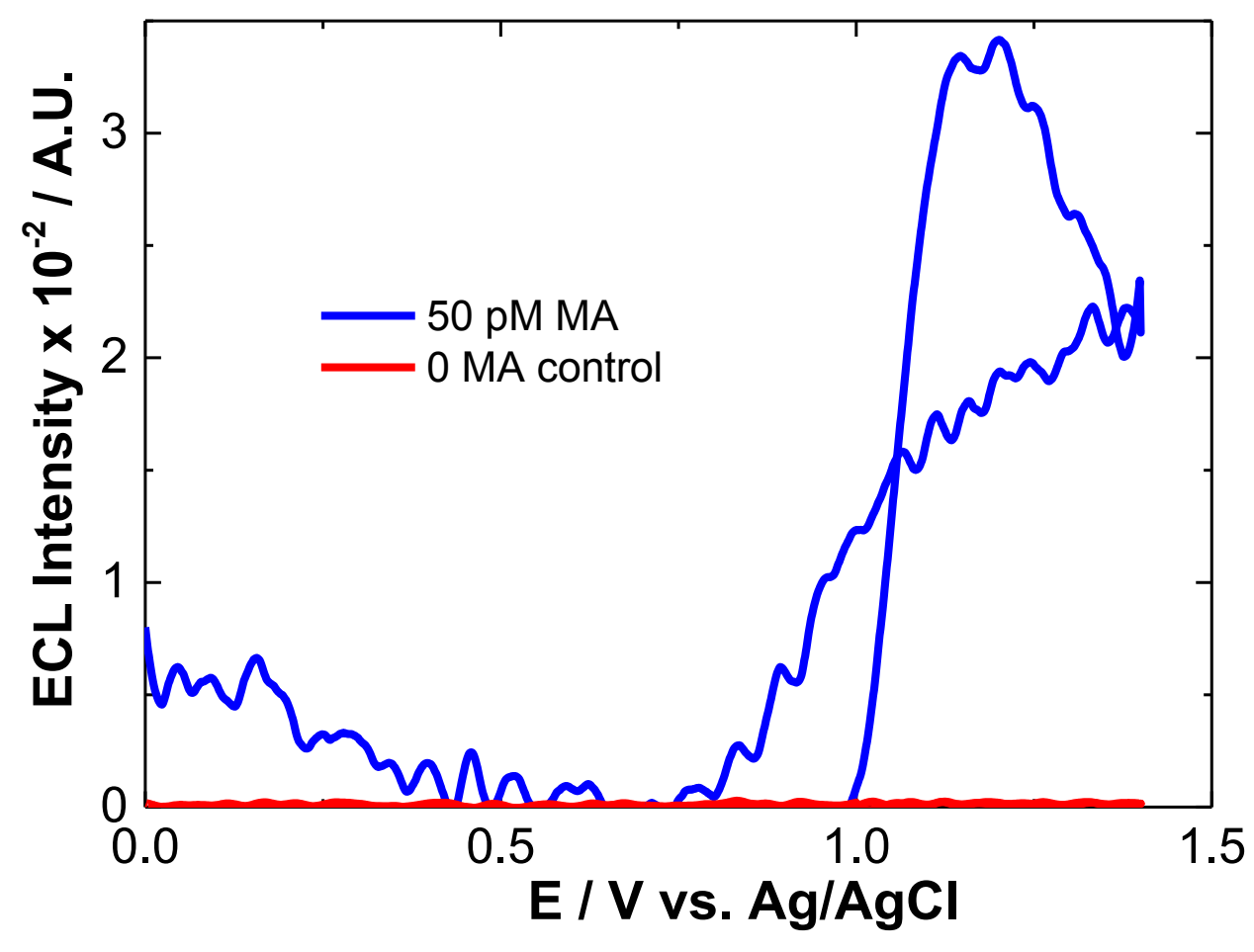


FIGURE 6

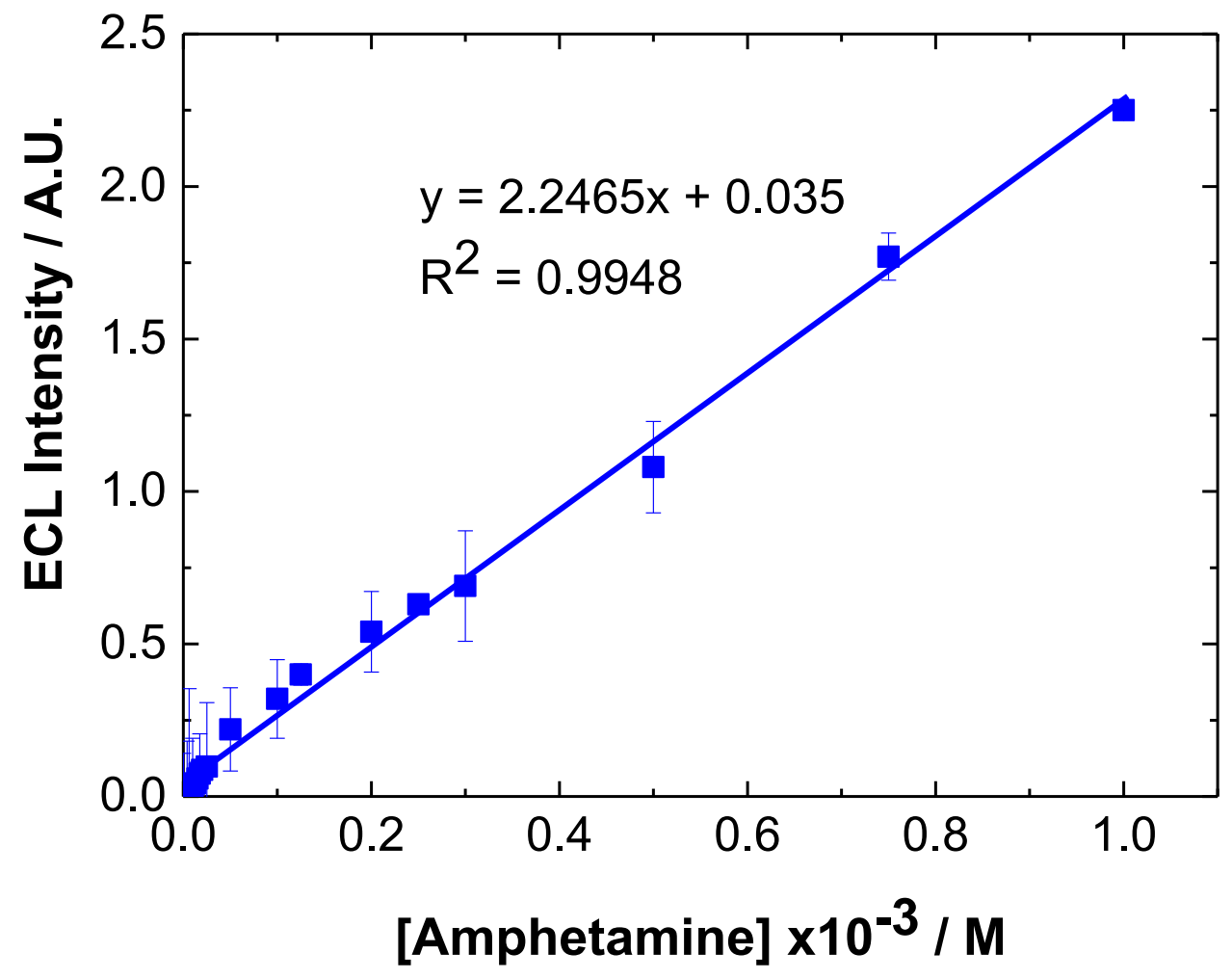


FIGURE 7

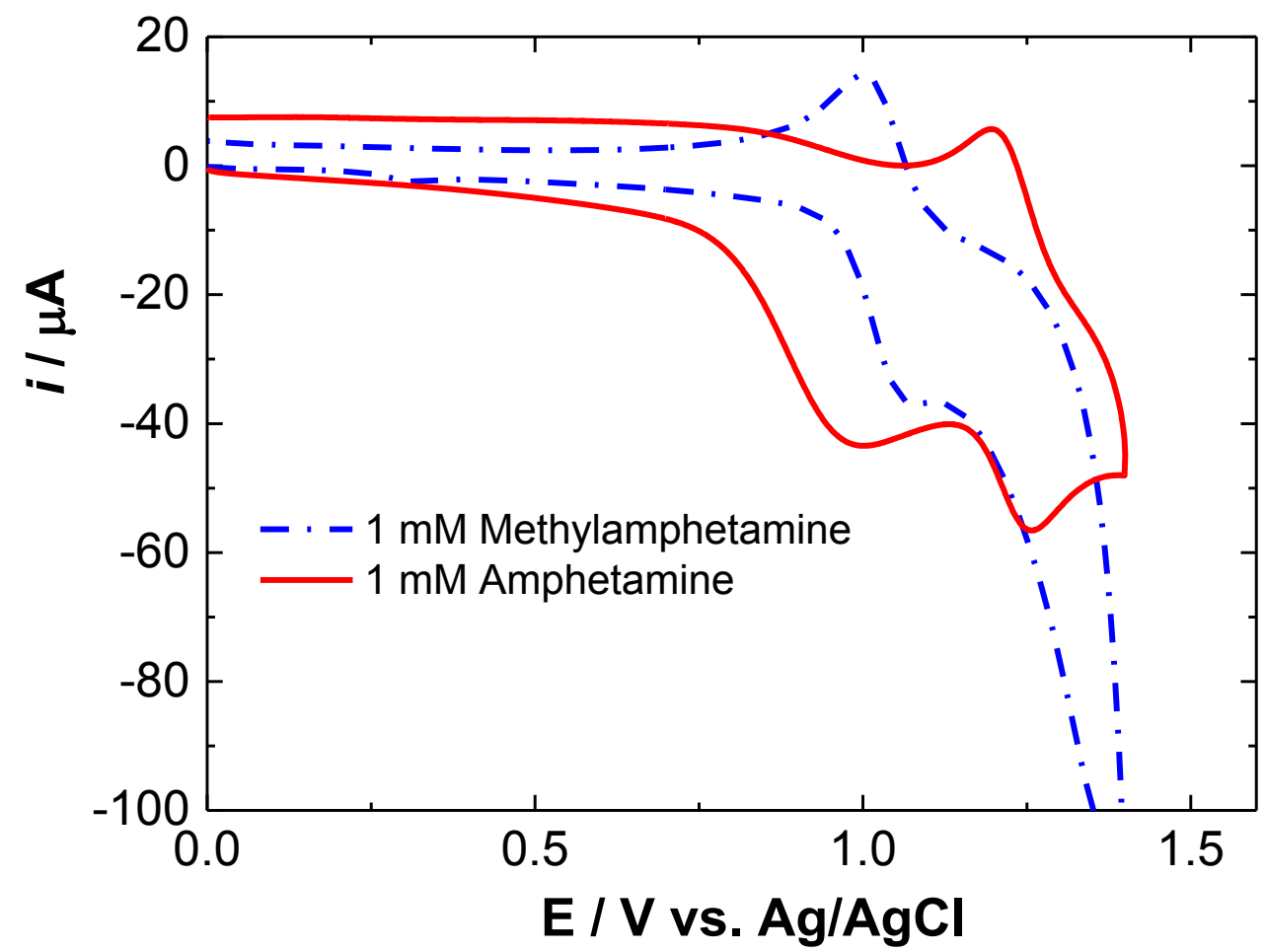


FIGURE 8

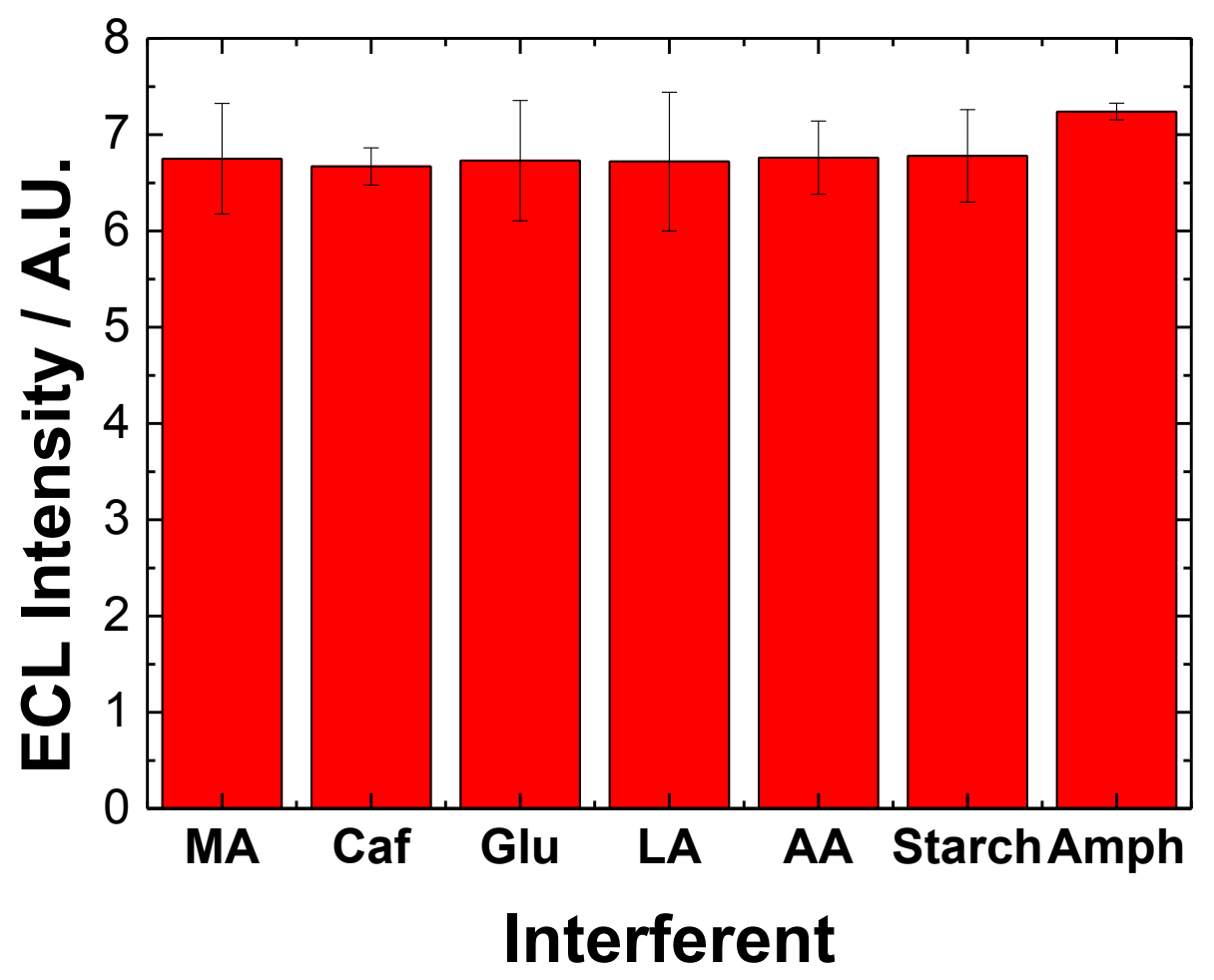


